\title{
SCURVY AND TUBERCULOUS PERITONITIS
}

\author{
BY
}

\author{
R. DERHAM, M.B., D.P.H., D.C.H. \\ From the Alder Hey Children's Hospital, and Department of Child Health, University of Liverpool
}

(Received for Publication, October 2, 1949)

Frank scurvy occurring in the later years of childhood has always been so uncommon that references in the literature are few. In 1894 Sutherland listed 71 cases: of these, only 14 were over the age of two years and only five were over the age of five years. In the United States scurvy in childhood (as distinct from infancy) has been termed ' a distinct rarity' (McIntosh). A case is, however, reported of a boy of seven years (Hartman and Friedman, 1931) who had been brought up on a diet containing little vitamin $\mathrm{C}$.

The following case of scurvy, first diagnosed at the age of 10 years and 11 months, is interesting, first because there was a previous history of tuberculous peritonitis associated with prolonged diarrhoea, and secondly because the child had exhibited dietetic habits of such perverseness that they might have been directed to the entire exclusion of ascorbic acid.

\section{Case Report}

Dorothy H. (born February 5, 1938) was brought to the Out-patient Department of. Alder Hey Children's Hospital, Liverpool, in December, 1948, with a limp. Intermittently during the previous 12 months she had complained of nocturnal pains in her legs, which had been sufficiently severe to make her cry. She had also had a sore mouth on many occasions since early childhood, and, during the preceding five weeks, her gums had shown a tendency to bleed.

Past illnesses included measles, whooping cough, and chickenpox. At the age of $5 \frac{1}{2}$ years (in September, 1943) the child had been taken to another hospital with a history of loose stools during the preceding three months and loss of weight. A diagnosis of tuberculous peritonitis was subsequently made and the child was in hospital for six months under the care of the late Dr. William Johnson. While in hospital the abdomen was described at first as 'doughy,' and later was distended (circumference $22 \frac{1}{2}$ in.). The child was afterwards observed as an out-patient until December, 1945, and her general condition was noted to be good, although her stools were once reported to be watery, and it was recorded at one time that she had a limp. There is no further medical record until she came to Alder Hey Hospital in December, 1948.

The child was found to be small for her age, her weight being $48 \mathrm{lb}$. and height $49 \mathrm{in}$. Examination of her mouth revealed petechiae on the hard palate, and the teeth were seen to be deeply pitted. There was oral foetor and the appearance of the gums was striking: they were deep purple in colour, swollen and fleshy, and they bled easily on palpation. A petechial rash was also noted on the buttocks, extensor aspects of the elbows, and dorsa of the feet. There was follicular hyperkeratosis over the anterior aspects of the legs. The right knee was slightly swollen and was tender over the inner aspect. Attempts at passive movement of this joint were resisted as, also, was rotation of the right hip joint.

Enquiry into the dietetic history revealed that the child would eat neither fruit nor green vegetables. She liked cooked meats but not potatoes, nor butter, and she would not drink milk. Her staple diet consisted of bread and margarine and her favourite beverage was tea with a very little milk. She consistently avoided milk and meals at school and would not visit the houses of friends unless special dishes were prepared for her. The perverseness of her appetite caused comment everywhere and her mother laboured continually to obtain the few things that she would eat. She had always been underweight, even in infancy. She had not been breast-fed and feeding had always been a problem. At the age of three years she was evacuated to Shropshire and there her diet had included a considerable amount of fruit, to which she had shown marked sensitivity with skin reactions.

The child was admitted to Alder Hey Children's Hospital on December 30,1948, for an initial period of observation and for biochemical and $\mathrm{x}$-ray investigation.

Blood Chemistry. On the day of admission the plasma ascorbic acid was $0.3 \mathrm{mg} . \%$ and the blood haemoglobin $92 \%$ (Haldane). The mean daily urinary ascorbic acid excretion was $4.3 \mathrm{mg}$. The capillary fragility, platelet count, bleeding, clotting and prothrombin times were all within normal limits. During this initial period of observation, lasting six days, the child received and took the ordinary ward diet. An ascorbic acid saturation test was then started, giving a daily test dose calculated at the rate of $70 \mathrm{mg}$. of ascorbic acid per stone of body weight. Specimens of urine were collected over a 21 -hour period, beginning four hours after the test dose. Low values $(0.8$ to $3.0 \mathrm{mg}$.) were obtained for the first five days, the figures then rising sharply on the sixth, seventh, and eighth days to $8.5 \mathrm{mg}$., $15.0 \mathrm{mg}$. and $36.0 \mathrm{mg}$. respectively. The serum calcium, inorganic phosphorus, and protein levels were estimated at the completion of the test 
and were all within normal limits. The serum alkaline phosphatase level was $20 \mathrm{King}$-Armstrong units.

Radiological Report. Radiographs of the long bones showed marked thinning of the cortex, and white lines of Fraenkel were especially prominent in the region of the knee joint (Fig. 1). Trabecular markings were fairly clear

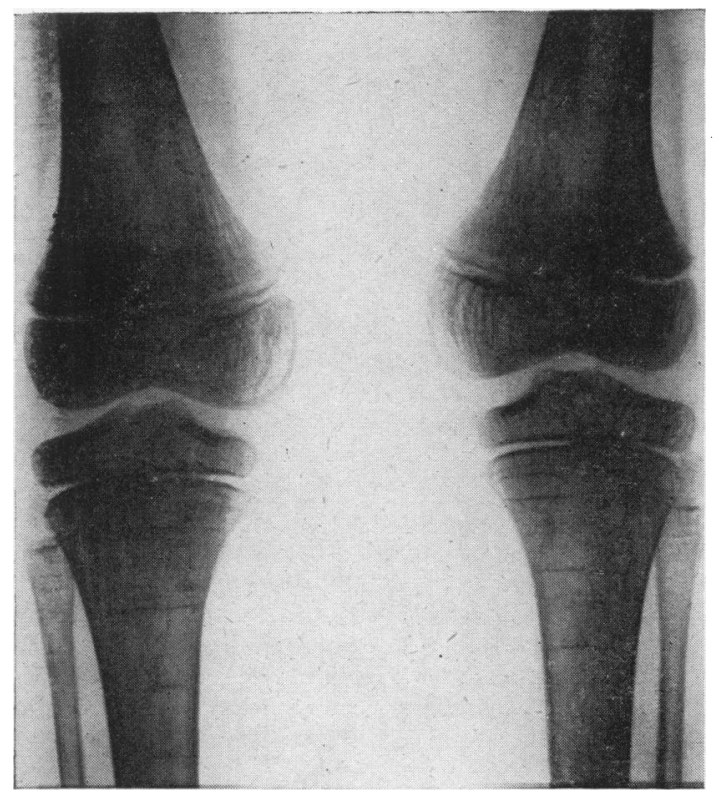

FIG. 1.-Radiograph of the long bones.

but the distal portions of the metaphyses showed some rarefaction and there were lateral spurs in the periosteum of the lower femoral diaphysis. Some swelling of the soft parts was also evident in the knee joints.

Dental Report. The gingivae were inflamed, painful and spongy, the papillae were haemorrhagic and grossly hypertrophied, and there was marked swelling over the site of the erupting second molars. The enamel of the incisor teeth was severely pitted from tip to the cervical margin and, on the facial aspect, showed some deficiency (Fig. 2). The periodontal membrane and alveolar bone seemed to have escaped gross disease because there was no loosening of the teeth.

Psychiatric Report. The child was of a gentle, reserved nature, lacking in self-confidence, anxious to please, but listless and hesitant in her responses. Her intelligence was estimated at 78 (revised Stanford Binet scale). The psychiatrist was of the opinion that the defective appetite had been present since birth: lack of breast feeding and early separation from the mother were thought to have some bearing on this. A great deal had been made of the child's poor appetite by her family and others, and she had consequently been the centre of attention. This appeared to have delayed her emotional development and made her unduly dependent upon her mother.

The conclusion was reached that during the past
18 months the deficiency in the child's diet had undermined her physical and mental energies to the extent that both intellectual and school progress had been hindered.

Treatment and Progress. After admission to hospital little difficulty was encountered in feeding the child. She ate the same meals as the other girls in the ward and readily relinquished her previous dietetic fads.

After the saturation test had been completed a dose of $25 \mathrm{mg}$. 'of ascorbic acid was given twice daily in addition to the normal ward diet: she received no other added vitamins.

There was a rapid improvement in her oral condition; the gums became firm and decreased in size, and the foetor disappeared. She gained $10 \mathrm{lb}$. in weight and 1 in. in height in two months. Concurrently with this physical improvement, her mental state showed a good response; she became more alert, cooperative, and interested in her companions. Her mental age advanced to 10 years and her intelligence quotient to 90 . She was no longer tired and never complained of pains in her limbs. The limp, however, proved more persistent, but physiotherapy with massage, active movements, and re-education enabled her to overcome this disability by the time she was discharged from hospital on February 24, 1949.

The child has been observed as an out-patient for six months since discharge. At the end of this time she was still improving mentally and, physically, was making good progress. She was still eating a normal diet, including fruit and green vegetables. She also continued to take $50 \mathrm{mg}$. of ascorbic acid daily.

\section{Discussion}

Interesting aspects of this case include the previous history of diarrhoea and tuberculous peritonitis, the unusual age at which gross manifestations of scurvy

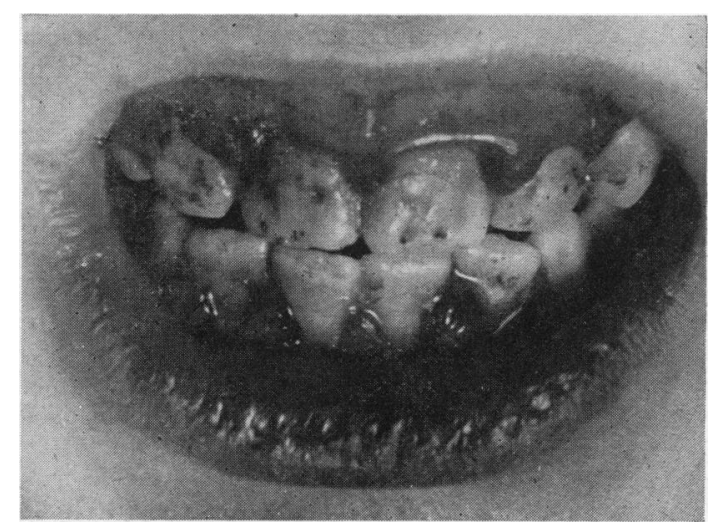

FIG. 2.-Photograph showing pitting of the enamel of the teeth.

became evident, the considerable physical retardation and emotional immaturity and the gratifying response to treatment.

It is difficult to ascertain for how long this child 
had suffered from a lack of vitamin $C$. The feeding difficulty was said to date from soon after birth. The radiological and dental pictures suggest chronicity and it had been noted, when the child was convalescing from tuberculous peritonitis, that she had a limp. It might be surmised either that a lack of vitamin C predisposed the child to tuberculosis, or that this latter condition, and the associated diarrhoea, precipitated the scurvy.

Many writers have considered the probability of a mutual relationship between scurvy and infections in general and tuberculosis in particular. The relationship between diarrhoea and vitamin $C$ lack has also been extensively studied.

Russell, Read, and Rouse (1944) found that scurvy led to extensive tuberculous lesions and widespread dissemination in experimentally infected guinea-pigs. Similar results had been obtained by Clausen (1934), Grant (1930), Greene, Steiner, and Kramer (1936), Steinbach and Klein (1941). Abbasy, Harris, and Ellman (1937) found that in patients with pulmonary tuberculosis there was a ' deficit in vitamin $C$ ' as shown by a lowered urinary excretion of the vitamin and a diminished response to a test dose; Abbasy, Gray Hill, and Harris (1936) also showed a low rate of excretion of vitamin C (an average of $9 \mathrm{mg}$. a day) in 23 cases of active surgical tuberculosis. Höjer (1924), in an extensive treatise, considered the two possibilities: the influence of tuberculosis on scurvy, and the influence of scurvy on tuberculosis. With regard to the former possibility he quotes Hess (1920): - Active tuberculosis is a not uncommon secondary manifestation' of scurvy. Höjer also points out that in tuberculosis there may be decreased appetite and the condition of the intestinal wall may become altered so that 'the consumed dose of antiscorbutic is prevented from having an effect.' On the other hand Höjer recorded that his observations 'lend countenance to the notion that the resistance of the body to tuberculosis is lessened during the course of scurvy.'

The antecedent history of diarrhoea is also likely to be relevant in this case. Hess and others drew attention to the occurrence of scurvy following dysentery during the 1914-1918 war. As early as 1892 Northrup reported a case of scurvy in a child aged three years suffering from diarrhoea. Abt and Farmer (1941) reported on three infants during the course of non-specific diarrhoea; they noted low plasma values and low urinary levels but an increase in faecal excretion of ascorbic acid when large amounts were given by mouth. Aron (1928) observed that scurvy might occur both in the infant and in the older child following dysentery or diarrhoeal diseases. Meyer and Robinson (1939) reported low levels of vitamin $\mathrm{C}$ in plasma and urine in infants suffering from diarrhoea in Palestine. (Several of the children in this series had bacillary dysentery.)

In the absence of vitamin $\mathrm{C}$ assessment at an earlier age, it does not seem possible, in this case, to decide whether the scorbutic tendency preceded the diarrhoea and tuberculous peritonitis, or whether these conditions precipitated the scurvy. As Abt and Farmer have said "diarrhoeal disturbance may initiate scurvy' and that may have been true of this case.

\section{Summary}

A case of scurvy is described in a girl of nearly 11 years. Her previous history included tuberculous peritonitis, and this may have had a relationship to the development of scurvy which was chronic in nature and was accompanied by physical and mental retardation. The aetiology is discussed and the result of treatment described.

I wish to thank Professor N. B. Capon for his most helpful criticism and advice, Dr. E. G. Hall for his willing cooperation and valuable comment on the pathological aspects, Dr. M. Barton Hall for the psychiatric opinion, Dr. W. Holden and Dr. J. A. Ross for radiological observations, and Professor $\mathbf{H}$. H. Stones and Mr. K. Richards for the dental report.

\section{REFERENCES}

Abbasy, M. A., Gray Hill, N., and Harris, L. J. (1936) Lancet, 2, 1413.

, Harris, L. J., and Ellman, P. (1937). Lancet, 2, 181

Abt, A. F., and Farmer, C. J. (1941). J. Pediat., 18, 756.

Aron, H. (1928). 'Die Närshchäden des Kindes', pp. 107-108. Vienna.

Clausen, S. W. (1934). Physiol. Rev., 14, 309.

Grant, A. H. (1930). Amer. Rev. Tuberc., 21, 115.

Greene, M. R., Steiner, M., and Kramer, B. (1936). Ibid., 33, 585.

Hartman, J. I., and Friedman, E. (1931). Amer. J. Dis. Child., 41, 337.

Hess, A. F. (1920). ' 'Scurvy, Past and Present.' Philadelphia.

Höjer, J. A. (1924). Acta paediatr., Stockholm (Supp.), 3,7 .

Meyer, L. F., and Robinson, P. (1939). Ann. Pediatr., $152,283$.

Northrup, W. P. (1892). Arch. Paediat., 9, 1.

Russell, W. O., Read, J. A., and Rouse, E. T. (1944). Arch. Pathol., 38, 31.

Steinbach, M. M., and Klein, S. J. (1941). Amer. Rev. Tuberc., 43, 403.

Sutherland, G. A. (1894). Practitioner, 52, 81. 